\title{
Transcatheter Atrial Septal Defect Closure: Preliminary Experience with the Rashkind Occluder Device
}

\author{
ROBERT H. BEEKMAN, M.D., ALBERT P. ROCCHINI, M.D., A. REBECCA SNIDER, M.D., \\ and AMNON ROSENTHAL, M.D.
}

From the Division of Pediatric Cardiology, Department of Pediatrics, C. S. Mott Children's Hospital, The University of Michigan, Ann Arbor, MI

The early experience at the University of Michigan with the Rashkind ASD occluder in three children with a secundum atrial septal defect $(A S D)$ is reported. Successful transcatheter ASD closure was accomplished in one child. The procedure was not successful in the other two. In one, the $A S D$ occluder was inadvertently implanted in the right atrium. The ASD was successfully closed in the

\section{Introduction}

During the past several years therapeutic catheterization techniques have been developed to provide nonsurgical treatment for children with congenital aortic valve stenosis, ${ }^{1,2}$ subvalvar aortic stenosis, ${ }^{3}$ mitral stenosis, ${ }^{4,5}$ and coarctation of the aorta. ${ }^{6,7}$ Transcatheter therapy is now generally regarded as the treatment of choice for children with valvar pulmonic stenosis, pulmonary artery stenosis, or postoperative recoarctation of the aorta. ${ }^{8}$ Transcatheter methods for closing shunt lesions have also been developed. Patent ductus arteriosus can be closed in the cardiac catheterization laboratory using a double-umbrella occluding device. ${ }^{9}$ Similarly, transcatheter closure of a secundum atrial septal defect (ASD) appears to be feasi-

Supported by the NIH General Clinical Research Center, Grant 3MO1-RR00042, Bethesda, MD.

Address for reprints: Robert H. Beekman, MD, Box 0204 , F1116, C. S. Mott Children's Hospital, Ann Arbor, MI 48109.

Submitted for publication December 21, 1988; accepted with revisions January 23, 1989. other child, but the occluder device partially detached from the atrial septum 4 days later and required emergency surgical retrieval from the left atritum. Based on this early experience, revisions in the occluder device and the technique of its delivery are suggested that should improve the safe'y and efficacy of transcatheter ASD occlusion in the future. (J Interven Cardiol 1989:2:1) ble. ${ }^{10,11}$ Since ASD accounts for approximately $8 \%$ of all congenital heart disease, the development of an effective nonsurgical technique for ASD closure would have an important impact on the treatment of children with heart disease.

In 1976, Mills and King reported the first transcatheter closure of a secundum atrial septal defect in humans using a double-umbrella device. ${ }^{10}$ During the 1970 s, Rashkind also developed a transcatheter closure device for use in patients with a secundum ASD. " Based on Rashkind's work in animals and humans, his occluder device has undergone multiple revisions. It currently consists of a single polyurethane foam disc supported by six stainless steel arms three of which support hooks designed to anchor the device to the atrial septum. The device is appropriate for closure of a small to moderate ASD measuring $<20 \mathrm{~mm}$ in its widest diameter, and has been approved recently by the FDA for clinical trials. The purpose of the present report is to describe our early experience with the Rashkind ASD occluder, and to recommend changes that may improve the safety and efficacy of transcatheter ASD occlusion in the future. 


\section{Technique}

Transcatheter ASD closure is presently an investigational procedure and has been approved by the institutional review board at our hospital. Appropriate informed consent is obtained, and surgical backup is available for all patients. The Rashkind ASD occluder (Fig. 1; USCI, Tewksbury, MA) is available in three sizes: $25 \mathrm{~mm}, 30 \mathrm{~mm}$, and $35 \mathrm{~mm}$ in diameter. We prefer to utilize an occluder whose diameter is approximately twice the largest diameter of the ASD. After the femoral vein is dilated serially with a 10,12 , and $14 \mathrm{Fr}$ dilator, a long $16 \mathrm{Fr}$ sheath is introduced percutaneously and advanced to the left atrium. ${ }^{11}$ With careful technique, we feel that the 16 Fr venous sheath can be safely used in children as small as 10 kilograms. The delivery system, with a collapsed occluder within its pod, is advanced through the sheath, across the ASD to the left atrium. Biplane fluoroscopy, and more recently two-dimensional echocardiography as well, is utilized to assure that the tip of the delivery system is located in the midportion of the left atrium. The venous sheath and pod are then retracted and the occluder is advanced slightly until it exits the delivery pod and opens within the left atrium. As the delivery catheter is then withdrawn, its centering arms guide the occluder device to the ASD. Firm traction is exerted on the catheter to embed the anchoring hooks firmly into the atrial septum. When all three hooks are seated, the occluder device is released from the catheter and the delivery system is removed from the femoral vein. A repeat right heart

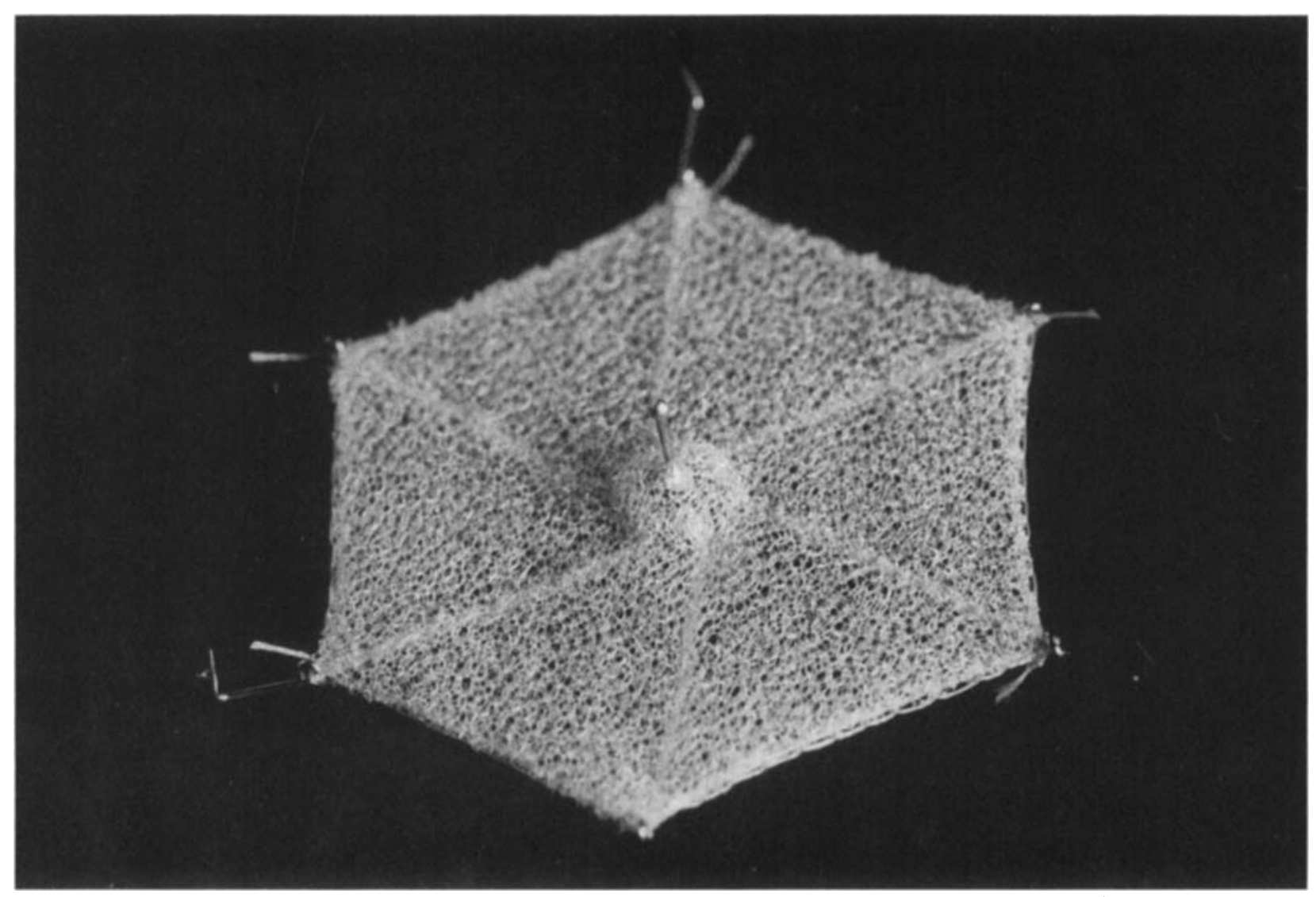

Figure 1. A 25-mm Rashkind ASD occluder device. The prosthesis is constructed of a hexagon of polyurethane foam material supported by six stainless steel arms. The arms are hinged centrally (not shown) to enable the device to fold into the delivery pod. Three of the arms are hooked to anchor the device to the atrial septum. In the center of the prosthesis is a beaded pin used to fasten the occluder to the delivery catheter. 


\section{TRANSCATHETER ASD CLOSURE}

catheterization is performed to quantitate any residual shunt that may be present. A pulmonary arteriogram is filmed to visualize the presence or absence of an atrial shunt on the levophase.

\section{Animal Experiments}

Prior to performing transcatheter ASD occlusion in humans, we utilized the technique to close an experimental ASD in four adult mongrel dogs. Each dog was anesthetized with intravenous suritol. The right femoral vein was entered percutaneously, and the left atrium catheterized transseptally using a Brockenbrough needle and a 7 Fr Mullins sheath. The atrial septal puncture was dilated with a $10-\mathrm{mm}$ balloon angioplasty catheter (Mansfield Scientific, Mansfield, MA, USA) to create a small ASD. Transcatheter ASD occlusion was then performed as described above, utilizing a 25-mm Rashkind occluder device. Each animal was sacrificed immediately and the heart examined.

In three animals the ASD occluder was properly seated on the left atrial septal surface, resulting in complete closure of the ASD. In a fourth animal, one of the anchoring hooks had caught within the left atrial appendage and caused the occluder to be malaligned as it was delivered to the atrial septum. Upon gross inspection, the prosthesis was only partially attached to the septum and did not occlude the ASD. No gross injury to the mitral valve was apparent.

\section{Case Reports}

Patient 1 was a 3 -year-old, $11.1 \mathrm{~kg}$, girl with a moderate secundum ASD. At cardiac catheterization the $\mathrm{Qp} / \mathrm{Qs}$ ratio was 1.8, and the ASD diameter measured $13 \mathrm{~mm}$ by angiography. Transcatheter ASD closure was attempted using a $25-\mathrm{mm}$ Rashkind occluder device. Under biplane fluoroscopic guidance the delivery pod was positioned in the left atrium, close to the atrial septum in an attempt to decrease the chance that an occluder hook might engage the atrial appendage or a pulmonary vein orifice. However, when the occluder was advanced from the delivery pod, it opened within the ASD and pulled itself through to the right atrium. The anchoring hooks attached to the lateral right atrial wall, and the device could not be retrieved transvenously. The inadvertent right atrial position of the occluder was confirmed by echocardiography. Later that evening the patient was taken to the operating room, where the occluder device was removed and the ASD repaired without complication. There was no apparent injury to the right atrial wall, eustachian valve or the tricuspid valve.

Patient 2 was an 8 -year-old, $22 \mathrm{~kg}$, boy also with a moderate secundum ASD. The diagnosis was confirmed at cardiac catheterization where the $\mathrm{Qp} / \mathrm{Qs}$ ratio was 1.8 , and the defect measured 13 $\mathrm{mm}$ in diameter by angiography. Because of the difficulty we encountered properly positioning the device in Patient 1 , both biplane fluoroscopy and two-dimensional echocardiography were utilized to assure that the delivery pod and the occluder were located in the midportion of the left atrium prior to seating the device on the atrial septum. Successful transcatheter ASD closure was accomplished using a $25-\mathrm{mm}$ Rashkind occluder, and the entire procedure took approximately 30 minutes (Fig. 2). The Qp/Qs ratio decreased from 1.8 to 1.1. A small residual left-to-right shunt was evident at the superior margin of the occluder by angiography and by Doppler echocardiography. Prior to discharge home the following day the child's physical exam had nearly normalized, although the second heart sound remained widely split. Mild cardiomegaly noted on chest X ray prior to ASD occlusion, had resolved.

A follow-up evaluation 6 months after the procedure indicated that the residual small left-toright shunt was no longer present. The physical exam, including the second heart sound, was completely normal. A two-dimensional echocardiogram documented a normal right ventricular dimension, normal septal motion, and there was no evidence of an atrial shunt by Doppler echocardiography. A radionuclide shunt study revealed no evidence of a residual shunt.

Patient 3 was a 6 -year-old, $20 \mathrm{~kg}$, boy with a small secundum ASD. Cardiac catheterization documented a Qp/Qs ratio of 1.6, and the defect measured $7 \mathrm{~mm}$ in diameter by angiography. The defect was occluded with a $25-\mathrm{mm}$ Rashkind occluder, again utilizing biplane fluoroscopy and echocardiography to position the device properly 

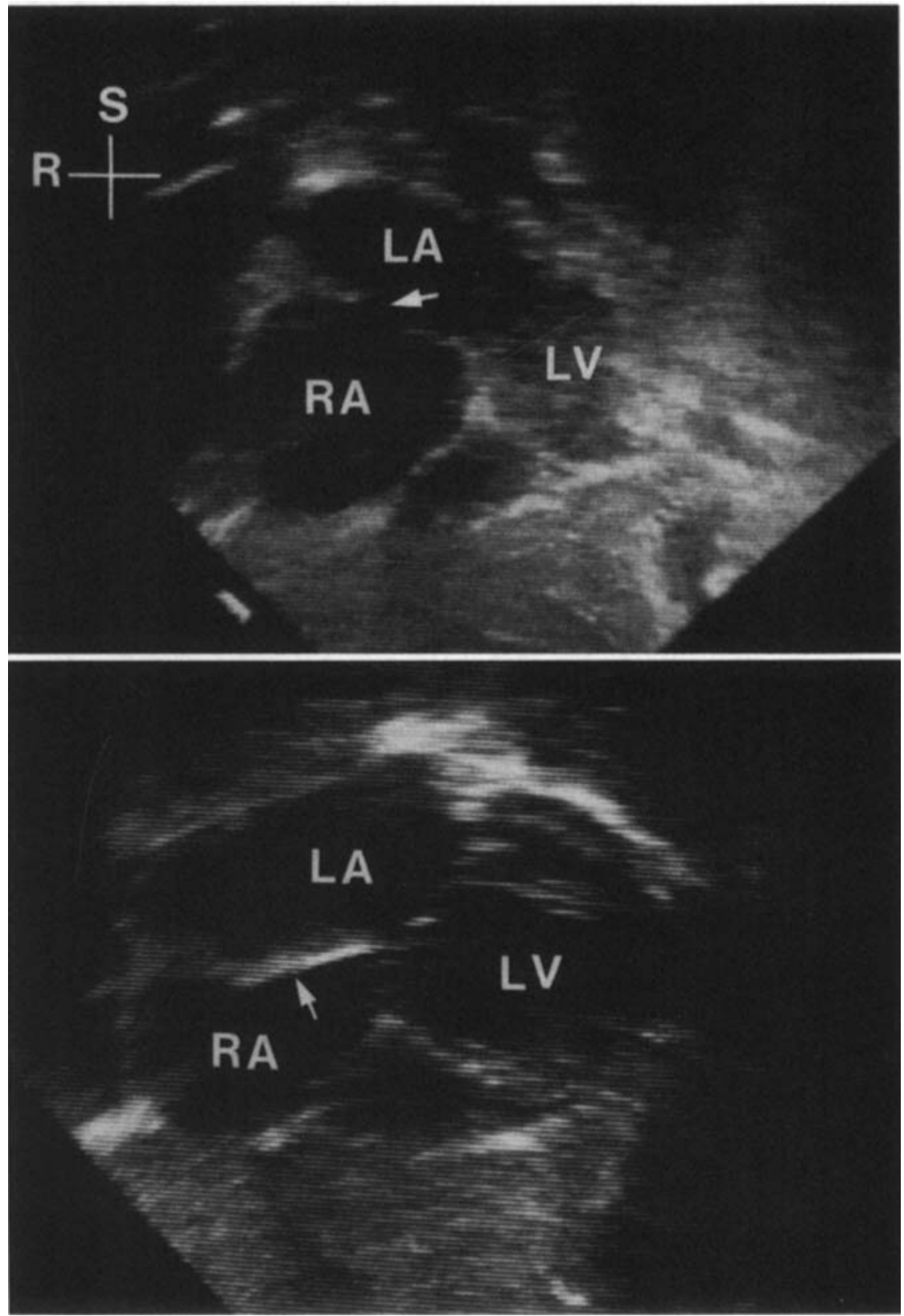

Figure 2. Two-dimensional echocardiogram, 4-chamber view, of Patient 2 before (upper panel) and after (lower panel) successful transcatheter ASD occlusion. In the upper panel, a 13-mm secundum ASD is evident (arrow). In the lower panel a $25-\mathrm{mm}$ Rashkind occluder device (arrow) has successfully occluded the defect. A small residual shunt at the margin of the device resolved 6 months after the procedure.

in the left atrium prior to occlusion. Immediately after ASD occlusion, one of the three hooked arms was noted to be bent slightly and did not appear to be attached firmly to the septum. Nevertheless, the
ASD was nearly occluded completely as only a very small residual shunt was detected angiographically. The patient was observed in a moderate care setting for two days. The physical exam normal- 
ized, and a repeat chest $X$ ray and two-dimensional echocardiogram documented that the device remained positioned properly on the atrial septum. A radionuclide shunt scan was normal, measuring a Qp/Qs ratio of 1.03 .

Four days following transcatheter ASD occlusion the child complained of palpitations. He was readmitted to the hospital where he was found to have sinus tachycardia, a widely split second sound, and murmurs of mitral stenosis and regurgitation. A two-dimensional echocardiogram revealed that the occluder device had detached partially from the atrial septum, and had rotated away from the septum to lie just above the mitral valve (Fig. 3). The patient was taken emergently to surgery where the occluder was removed and the ASD repaired. A tiny puncture in the posterior leaflet of the mitral valve was sutured. Postoperatively the child has done well, with only trivial mitral regurgitation evident 1 year following surgical repair.

\section{Discussion}

Clinical experience using the Rashkind ASD occluder has been extremely limited. Rashkind has reported his early experience using the single-disc occluder to close a small to moderate sized secundum ASD in 23 children and adults. ${ }^{11,12}$ Satisfactory closure was achieved in 14 patients $(61 \%)$. However, in nine the closure was considered unsatisfactory because of improper implantation or the persistence of a significant left-to-right shunt. Six of these nine children subsequently underwent surgical ASD repair. Retrieval of the occluder device and surgical ASD closure were reportedly uncomplicated.

Our preliminary experience with the Rashkind ASD occluder device in three children with a secundum ASD has also been mixed. Although successful ASD closure was accomplished in one child, in two others transcatheter closure was not successful and surgical ASD repair was required. On the basis of our initial experience a number of observations can be made. First, transcatheter ASD occlusion is clearly feasible. This is indicated both by the successful closure of a moderate secundum ASD in one child in our series, and by Rashkind's early experience with the prototype single-disc ASD occluder. Second, our experience indicates that a small residual shunt present at the margin of the occluder immediately after transcatheter closure may resolve with time. In patient 2 , a small left-to-right shunt persisted at the upper margin of the occluder device after transcatheter ASD occlusion. Follow-up physical examinations, echocardiograms, and a nuclear shunt scan documented that this residual shunt had resolved completely by the sixth month after transcatheter closure. The process by which this may have occurred is unclear, but most likely involves endothelial ingrowth along the margin of the occluder device.

Although the series is small, our unsuccessful attempts at transcatheter ASD closure in two children highlight several deficiencies in the present occluder device and delivery system. First, because of its anchoring hooks the current device cannot be withdrawn into the delivery system or its position adjusted significantly once it is advanced out of the delivery pod. Thus, unlike the double-umbrella PDA occluder, the single-disc ASD occluder is an "all or none" device whose implantation is committed once it is opened within the left (or right) atrium. Second, the current ASD occluder device may become dislodged from the septum if all three hooks are not attached perfectly to the atrial septal surface. If only one hook is poorly anchored, then $240^{\circ}$ of the device remains essentially unsupported and vulnerable to dislodgement as experienced by patient 3 in our series. Third, the current delivery system may not deliver the occluding device parallel to the atrial septum. As the device is pulled toward the left septal surface, the delivery catheter is withdrawn inferiorly into the inferior vena cava and appears to tilt the occluding device so that it is no longer parallel to the atrial septum. This may result in malalignment of the device on the septum, and incomplete closure of the septal defect. ${ }^{13}$

These observations suggest a number of potential revisions that may improve the efficacy and safety of transcatheter ASD occlusion in the future. Alterations in the ASD occluder device itself will be necessary. An occluder device that does not attach by hooks to the atrial septum would allow the potential benefit of withdrawal back into the delivery system if its initial position were deemed unsatisfactory. In 1983 Rashkind, recognizing similar drawbacks of the single-disc device, proposed that a double-disc occluding system may be 

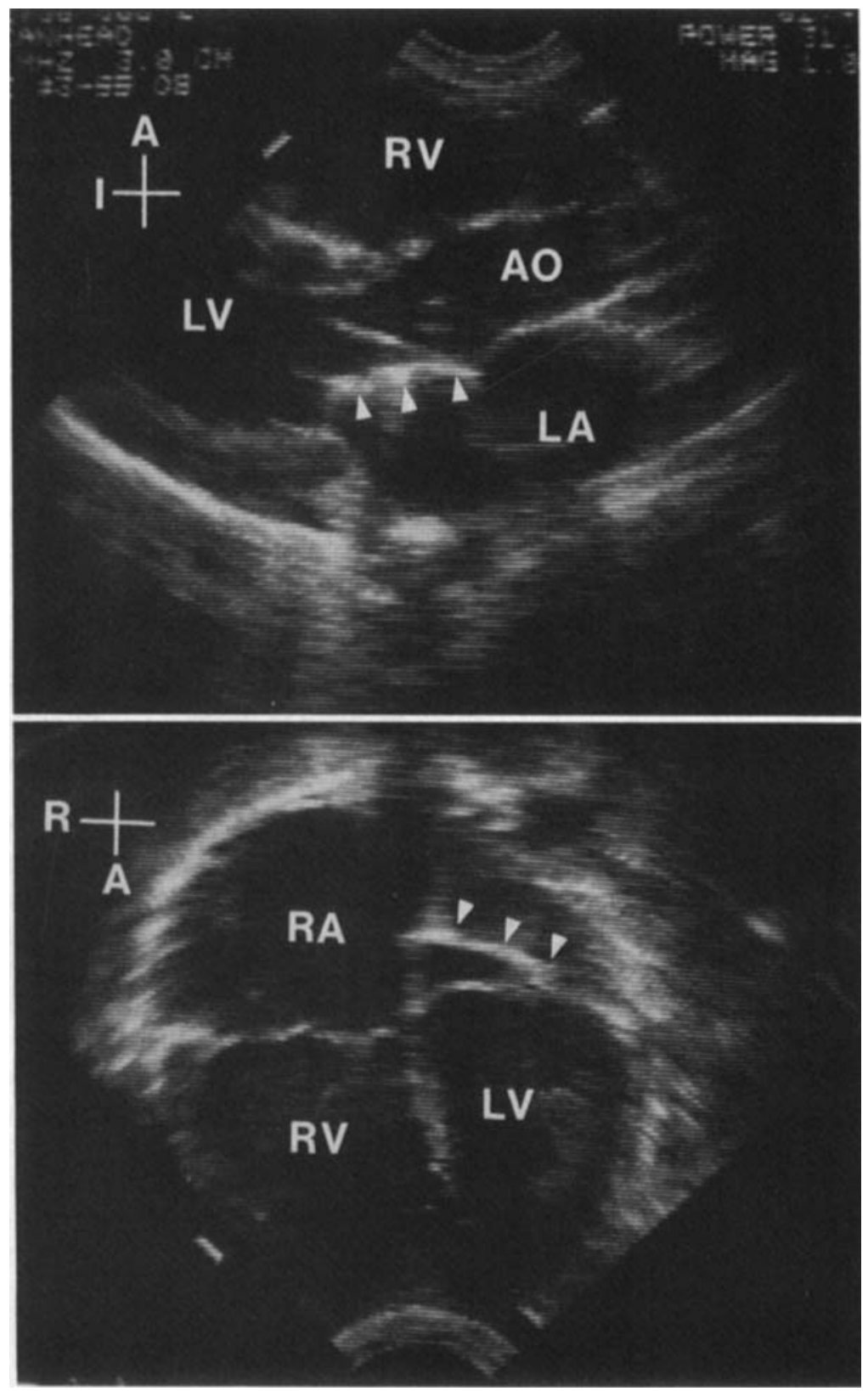

Figure 3. Two-dimensional echocardiogram of Patient 3, obtained 4 days after transcatheter ASD occlusion, show that the occluder has partially dislodged from the septum. A parasternal long-axis view (upper panel) and apical 4-chamber view (lower panel) demonstrate that the prosthesis has rotated off of the atrial septum into the left atrium. It lies just above the mitral valve, and is drawn into the mitral valve funnel during diastole (arrowheads).

preferable. It is not clear from the description whether his double-disc system was dependent upon anchoring hooks for attachment to the septum. Recently, however, Sideris ${ }^{14}$ and Rome ${ }^{15}$ have demonstrated that a hookless double-disc device can be utilized to successfully occlude experimental atrial septal defects.

We also recommend that two-dimensional 


\section{TRANSCATHETER ASD CLOSURE}

echocardiography be utilized, together with biplane fluoroscopy, to assist in properly locating and positioning the device within the left atrium before it is seated on the atrial septum. Echocardiography can accurately determine the location of the delivery pod in the midleft atrium before the occluder device is opened. We feel that the use of echocardiography in Patient 1 may have prevented the inadvertent opening of the occluder in the proximal left atrium that resulted in its implantation along the right atrial wall. Finally, revisions in the delivery system must also be considered. For example, the use of a curved delivery sheath may improve the technique by delivering the occluder in a more parallel fashion to the atrial septum.

Transcatheter occlusion of a secundum ASD is a promising, nonsurgical approach to the treatment of this common congenital heart defect. The current technique has a number of drawbacks that appear to have limited its successful application. As highlighted by our experience, these relate both to the occluder device itself and to the method of its delivery. We are certain, however, that with continued experience and appropriate revisions in the technique, transcatheter ASD occlusion will become a safe and effective treatment for children with a secundum ASD in the future.

Acknowledgments: The authors gratefully acknowledge the technical assistance of William E. Hellenbrand, MD, and the advice of Larry $A$. Latson, MD regarding the technique of transseptal left atrial catheterization in the dog.

\section{References}

1. Choy M, Beekman RH, Rocchini AP, et al. Percutaneous balloon valvuloplasty for valvar aortic stenosis in infants and children. Am J Cardiol 1987; 59:1010-1013.

2. Walls JT, Lababidi Z, Curtis JJ, et al. Assessment of percutaneous balloon pulmonary and aortic valvuloplasty. $J$ Thorac Cardiovasc Surg 1984; 88:352-356.

3. Lababidi $Z$, Weinhaus $L$, Stoeckle $H$, et al. Transluminal balloon dilatation for discrete subaortic stenosis. Am J Cardiol 1987; 59:423-425.

4. Kveselis DA, Rocchini AP, Beekman RH, et al. Balloon angioplasty for congenital and rheumatic mitral stenosis. Am J Cardiol 1986; 57:348-350.

5. Lock JE, Khalilullah M, Shrivastava S, et al. Percutaneous catheter commissurotomy in rheumatic mitral stenosis. $\mathbf{N}$ Engl J Med 1985; 313:515-518.

6. Beekman RH, Rocchini AP, Dick M, et al. Percutaneous balloon angioplasty for native coarctation of the aorta. J Am Coll Cardiol 1987; 10:1078-1084.

7. Lababidi ZA, Daskalopoulos DA, Stoeckle H. Transluminal balloon coarctation angioplasty: Experience with 27 patients. Am IJ Cardiol 1984; 54:1288-1291.

8. Lock JE, Keane JF, Fellows KE. The use of catheter intervention procedures for congenital heart disease. J Am Coll Cardiol 1986; 7:1420-1423.

9. Rashkind WJ, Mullins CE, Hellenbrand WE, et al. Nonsurgical closure of patent ductus arteriosus: Clinical application of the Rashkind PDA occluder system. Circulation 1987; 75:583-592.

10. Mills NL, King TD. Non-operative closure of left-to-right shunts. J Thorac Cardiovasc Surg 1976; 72:371-378.

11. Rashkind WJ. Interventional cardiac catheterization in congenital heart disease. Int J Cardiol 1985; 7:1-11.

12. Rashkind WJ. Transcatheter treatment of congenital heart disease. Circulation 1983; 67:711-716.

13. Lock JE, Cockerham JT, Keane JF, et al. Transcatheter umbrella closure of congenital heart defects. Circulation 1987; 75:593-599.

14. Sideris EB, Fowlkes JP, Smith JE, et al. Transvenous atrial septal defect occlusion in piglets (Abstr). Circulation 1988; 78:II-99.

15. Rome JJ, Keane JF, Perry S, et al. Atrial Septal Defects: Anatomic Study and Experimental Catheter Closure (Abstr). Circulation 1988; 78:II-99. 